\title{
Parental background and housing outcomes in young adulthood
}

\section{Rory Coulter}

To cite this article: Rory Coulter (2016): Parental background and housing outcomes in young adulthood, Housing Studies, DOI: 10.1080/02673037.2016.1208160

To link to this article: http://dx.doi.org/10.1080/02673037.2016.1208160
(c) 2016 The Author(s). Published by Informa UK Limited, trading as Taylor \& Francis Group
曲 Published online: 11 Aug 2016.

Submit your article to this journal $\pi$

Џلll Article views: 467

Q View related articles $\llbracket$

View Crossmark data $\nearrow$

Citing articles: 1 View citing articles $₫$ 


\title{
Parental background and housing outcomes in young adulthood
}

\author{
Rory Coulter (iD \\ Department of Sociology, University of Cambridge, Cambridge, UK
}

\begin{abstract}
Scholars and policy-makers are concerned that young adults' housing opportunities are becoming more dependent on their family background. This could hinder social mobility and exacerbate inequality. Using data from three cohorts of young people drawn from the Office for National Statistics Longitudinal Study of England and Wales, this study examines how parental attributes in childhood are linked to young adults' housing outcomes two decades later. The results show that young adults' housing outcomes have changed considerably over time and are persistently stratified by parental class and tenure in ways that vary by gender. Housing outcomes have become somewhat more polarised by parental tenure over time as the children of renters became relatively less likely to enter homeownership and more likely to rent privately. This suggests that renters became an increasingly 'marginalised minority' in the late twentieth century, with consequences for their children's housing careers and future social inequality.
\end{abstract}

\section{ARTICLE HISTORY}

Received 22 June 2015

Accepted 23 December 2015

\section{KEYWORDS}

Family; housing tenure;

intergenerational transmission; stratification; young adults

\section{Introduction}

British policy-makers are becoming increasingly concerned about young adults' housing careers. Faced with rising rates of private renting ${ }^{1}$ the government has intervened to support owner-occupation by providing mortgage guarantees and equity loans to first-time buyers through the 'Help to Buy' scheme. At the same time, research shows how a lack of affordable housing options is stretching household budgets and compelling young people to adjust their living arrangements, often by sharing their dwelling or staying in the parental home (Gardiner \& Alakeson, 2014; Shelter, 2014). Variants of these trends are being experienced across Europe and are contributing to the growing fluidity, diversity, protraction and precarity of young Europeans' transitions to adulthood (Clapham et al., 2014; Lennartz et al., 2015; Stone et al., 2011).

Evidence that housing is a major component of wealth holdings indicates that current and future socio-economic inequalities are shaped by young adults' housing trajectories (McKee, 2012). Many authors argue that the timing of homeownership transitions is particularly crucial because owner-occupancy typically reduces lifetime housing costs whilst 
providing security, tax advantages, collateral and the opportunity to accumulate and release equity (Appleyard \& Rowlingson, 2010; Lersch \& Luijkx, 2015; Saunders, 1990). In The Pinch (2011), David Willetts argued that the 'Baby Boom' cohort born immediately after the Second World War benefited uniquely from affordable homeownership and subsequent house price inflation. Willetts proposed that these gains deepened inter-generational inequality by pricing later cohorts out of owner-occupancy, especially after the Global Financial Crisis when mortgages were harder to come by. This indicates that the ageing of Western societies could be 'doubly disadvantaging' young people, who are finding it hard to access homeownership at the same time as the looming challenge of financing pensions, health services and care threatens their income prospects.

Many authors are also concerned that family support is becoming increasingly critical for young adults seeking to enter and navigate the housing system (McKee, 2012; NHF, 2014). On the one hand, increased enrolment in higher education, curtailed welfare support and an insecure labour market mean that many young people use the parental home as 'safety net' accommodation (Stone et al., 2014). Unemployment and economic inactivity thus increase the odds that young Britons live with their parents (Stone et al., 2011), although delayed home-leaving is also a strategy to save up for homeownership (Ermisch \& Halpin, 2004). Importantly, partnership patterns and welfare policies mean that men and women draw differently on parental safety nets (Stone et al., 2014). For example, most lone parent households are headed by women who thus benefit from the high priority social housing providers assign to families with dependent children.

Families may also be becoming more important for young adults' housing careers because credit constraints, high rents and house prices, low wages and the burden of student debt mean that a growing proportion of young people need financial assistance when buying a dwelling (NHF, 2014; Tatch, 2007). This often comes in the form of familial gifts or loans towards mortgage deposits (Helderman \& Mulder, 2007). Many young people also require financial and 'in-kind' support from their parents just to live independently (Heath \& Calvert, 2013). Taken together, these trends suggest that family and especially parental background increasingly shapes young people's housing options (McKee, 2012). Kennett et al. (2013) argue that this is one outcome of a broader elite-driven project aimed at transforming Western societies by displacing responsibility for housing and welfare support from the state onto families and individuals.

Parental effects on young adults' housing trajectories could, however, create tensions between this agenda and Western governments' espoused commitment to social mobility. Although much social mobility research concentrates on the intergenerational transmission of human capital or occupation, the volatility and spatial polarisation of house prices and rents means that young people's long-term economic prospects are strongly influenced by their housing trajectory (Hamnett, 1999). Housing options also shape human capital and career progression by enabling or constraining residential mobility (Ermisch \& Halpin, 2004). Analysing how families influence housing tenure and living arrangements in young adulthood under different institutional arrangements is therefore important for understanding intergenerational transmissions of (dis)advantage (Kurz \& Blossfeld, 2004).

In Britain, comparatively little is known about three aspects of the link between family background and young adults' housing outcomes. First, there is considerable uncertainty about the relative importance of different parental attributes and the mechanisms through which these operate. On the one hand, Saunders (1990) argued that parental tenure is crucial 
as owners and renters have different property rights and relations to the state. Homeowners' lower housing costs and their ability to accumulate, access and bequeath equity mean that they tend to have greater means and opportunity to support their children than tenants (Mulder \& Smits, 2013). Homeowning parents may also socialise their children towards owner-occupation and away from renting by shaping their tenure knowledge, preferences and aspirations (Henretta, 1984). Resource and socialisation effects both seem to explain intergenerational continuities in homeownership in continental Europe (Blaauboer, 2010; Lersch \& Luijkx, 2015; Mulder \& Smits, 1999; Spilerman \& Wolff, 2012), although inheritance may become relevant later in life (Appleyard \& Rowlingson, 2010).

While Di Salvo \& Ermisch (1997) showed that parental owner-occupancy accelerates young adults' homeownership transitions, there has been considerable debate about how intergenerational tenure continuities are affected by the sorting of parents into tenures on the basis of socio-economic position (Forrest \& Murie, 1995). In one view, it is the weaker socio-economic position of tenants, rather than their tenure, that explains the lower likelihood of their children becoming homeowners (Jenkins \& Maynard, 1983). Indeed, Watt (1996) showed that both class and tenure matter for young people's housing outcomes. Similarly, while growing up in a lone parent household is associated with socio-economic disadvantage, it is not known whether childhood family structure matters for housing outcomes once parental socio-economic position and tenure are taken into account (Blaauboer, 2010; Öst, 2012). Disentangling the effects of parental attributes is tricky because these may be mediated or moderated by young adults' life course development, for example through intergenerational continuities in occupation or the tendency for people to choose partners with matching characteristics (Ermisch \& Halpin, 2004; Mulder \& Smits, 1999).

A second neglected issue is the long-term association between parental attributes and housing outcomes. Although several British studies have examined the association between parental attributes and young people's housing trajectories, these relied on small samples gathered when a large proportion of households rented from Local Authorities (Jenkins \& Maynard, 1983; Murphy, 1984; Payne \& Payne, 1977). More recent nationally representative analyses have, by contrast, tended to use relatively short portions of panel data to examine parental effects on transitions in and out of the parental home or into homeownership (Andrew, 2012; Ermisch, 1999; Stone et al., 2014). These studies have shown how contextual forces shape young adults' housing transitions. For example, high house prices and unemployment rates inhibit young people's household formation and homeownership (Clark \& Mulder, 2000; Di Salvo \& Ermisch, 1997; Ermisch, 1999).

Whilst valuable, analysing transitions can tell us little about the cumulative long-term impacts of parental characteristics. This is problematic because parental attributes may have divergent short- and long-term effects, for example if parental affluence discourages early home-leaving while increasing the eventual odds of homeownership (Ermisch, 1999). As studies of occupational social mobility have shown, it is these long-term intergenerational associations that best measure the changing fluidity of societies (Platt, 2005).

Due to data constraints, few studies have assessed whether the impacts of parental background have changed over time. Although cross-sectional data show that broader trends of declining homeownership and rising shared living in young adulthood are evident in Britain (Andrew, 2012; Stone et al., 2011), it is not clear whether family background stratifies these broad patterns. As welfare, labour market and housing systems shape young people's life courses we cannot assume that trends documented for the Netherlands (Smits 
\& Mulder, 2008) and Sweden (Öst, 2012) apply equally to Britain. In any case, it is important to assess whether cohort effects are due to the changing nature of young adults' life courses (for instance, delayed partnership formation) or contextual factors (such as house prices or labour market structures) (Clark \& Mulder, 2000). Such knowledge is important for designing interventions to support young adults' housing careers.

In the light of the above, this study asks how are young adults' housing outcomes associated with the attributes of their parents, and have these patterns changed over time? Particular attention is paid to two issues. First, the paper considers how the absolute and relative odds of housing outcomes vary by cohort and parental background. While the absolute odds of each outcome matter to individuals (Watt, 1996), comparing the odds of young people from different backgrounds enables us to measure inequalities in life chances while controlling for changes in the opportunity structure (Platt, 2005). Second, the study examines how the associations between parental background and young adults' housing outcomes are affected by life course trajectories and contextual conditions. The paper concentrates on England and Wales as these countries have similar tenure structures and a largely shared history of housing policy. By contrast, the social rental sector has traditionally housed a larger proportion of Scottish households, while housing in Northern Ireland is bound up with a historic legacy of community division.

\section{Data and methods}

\section{Data and sample}

Data are drawn from the Office for National Statistics Longitudinal Study of England and Wales (LS). The LS is a relational database containing the linked decennial census records of a one per cent sample of the population of England and Wales. The initial sample comprised all individuals in the 1971 census born on one of four specific birth dates. Immigrants and new babies with these birthdays are continuously added to the sample so that it remains representative (Buxton et al., 2005). Census data about individuals living with Longitudinal Study Members (LSMs) are available, although these individuals are not followed through time.

The LS is useful for this project as it tracks a very large sample of individuals over long periods of the life course. Although relatively little is known about LSMs between each census, the long duration of the LS means that childhood conditions can be linked to later life outcomes without relying on retrospective reports. As the LS spans a long period of historical time, we can also examine how housing outcomes vary by birth cohort. A final advantage is the low level of attrition. While some gaps in coverage are inevitable due to under-enumeration and unrecorded deaths or emigration, over 85 per cent of eligible LS records have been successfully linked across each intercensal period. This compares very favourably with the retention rates of most longitudinal surveys, although the rather limited range of variables available in the LS does mean that analysis is restricted to broad patterns of statistical relationships rather than micro-level social processes.

The sample consists of all LSMs aged 10-14 and usually resident in a private household with a parent at the 1971, 1981 or 1991 censuses. Children aged 15 and above were excluded to ensure that all were dependent at their baseline census. ${ }^{2}$ LSMs were dropped if they were not enumerated at their $t+1$ and $t+2$ census when aged 20-24 and 30-34 respectively, or if they entered a communal establishment such as prison or institutional care. A handful of cases missing key data were removed to leave 72120 individuals. 
This sample was divided into three cohorts: Baby Boomers born 1956-1961 during the postwar peak in the birth rate (13 205 men and 13698 women tracked 1971-1991); Post Boomers born 1966-1971 (11 904 men and 13648 women tracked 1981-2001); and Generation X born 1976-1981 during a trough in the birth rate (9280 men and 10385 women tracked 1991-2011). Baby Boomers, Post Boomers and Generation X were thus aged 10-14 in 1971, 1981 and 1991, respectively. In each cohort, the sample is slightly larger for women because LS linkage rates are lower for men. ${ }^{3}$

\section{Measures}

The dependent variable was measured when LSMs were aged 30-34. By this age, many people have completed their formal education, started labour force careers and formed partnerships and families (Mulder \& Smits, 1999). Residential mobility rates also fall from the late 20 s and thus the housing circumstances of individuals aged 30-34 often signpost the direction of their longer term housing trajectory (Clark \& Mulder, 2000; Di Salvo \& Ermisch, 1997). Focusing on outcomes at a consistent age permits cohort comparison but can tell us less about changes in the biographical timing of events.

The dependent variable has four unordered categories. Information on household tenure was used to code LSMs as owner-occupiers (category 1), social tenants (2) or private tenants (3) if they lived alone or with only a partner and/or their own children. These people live in single-family households where they can be assumed to be (partly) responsible for the dwelling. By contrast, those enumerated as living with a parent or other adult(s) were coded as 'living with parents or sharing' (category 4), regardless of household tenure. While pooling individuals in the parental home with those in other multi-adult households overlooks how these groups differ in terms of tenure arrangements and housing pathways, sample size limitations and uncertainties about some relationships within complex households make disaggregation impractical. ${ }^{4}$ Moreover, it is not possible to identify 'who lives with who' in these households as the census does not gather information on which individual owns or rents the dwelling. Information on the identity of the householder cannot be used to proxy dependency as the way the census classifies householders has changed over time.

Parental attributes were measured when LSMs were aged 10-14. As lone parenthood may correlate with lasting socio-economic disadvantage a dummy identifies children living with one parent. To capture differences in class background and family resources, parental occupational class is coded using the National Statistics Socio-Economic Classification (NS-SEC) schema introduced in 2001 and approximated for earlier censuses. ${ }^{5}$ Four categories are distinguished: higher managerial, administrative and professional occupations (NS-SEC 1-2); intermediate occupations (NS-SEC 3-4); routine and manual occupations (NS-SEC 5-7); and a few individuals where NS-SEC could not be defined. In line with previous work, the higher status parental NS-SEC code was assigned when an LSM lived with two parents (Platt, 2005). ${ }^{6}$

Parental tenure is divided into owner-occupation, social tenancy and private tenancy in order to capture intergenerational correlations in homeownership and the potential inheritance of some types of social tenancy. A variable measures the age gap between the LSM and their youngest co-resident parent as younger parents have less time to accumulate resources to support their children (Mulder \& Smits, 2013). It was not possible to define 
a robust variable to capture the number of siblings at baseline as the LS does not contain data on kin living outside the household.

Control variables were defined for age and ethnicity. A dummy captures whether the LSM had a long-term limiting illness or disability aged 30-34 as this could increase their eligibility for social housing and their propensity to live with a carer. Dummies identify LSMs living with their children when aged 20-24 and 30-34 as families with children are allocated a high priority for social housing. Partnership and labour force participation variables are defined when aged 20-24 and 30-34. These classify singles by whether or not they are working and couples according to the employment participation of both partners. Educational attainments are measured with a dummy for higher degrees, ${ }^{7}$ while occupational status is defined when 30-34 using the procedure outlined for parents. Dummies are defined for intercensal migration between regions.

As housing outcomes are constrained by tenure structures a variable measures the percentage of owner-occupier households in the Local Authority (LA) district. Higher levels of owner-occupation mean that there is less rental housing available and individuals who cannot buy may be less able to live independently. Mean regional house prices for first-time buyers are controlled as Ermisch (1999) showed that higher house prices increase intergenerational co-residence and lower young adult homeownership. ${ }^{8}$ Gender-specific regional unemployment rates amongst 30-34 year olds are included to capture the association between labour market conditions and housing outcomes. Due to data constraints all contextual variables are measured when 30-34. The effects of these variables should thus be interpreted as correlations rather than the causal impact of conditions experienced earlier in life. Summary statistics for all independent variables are shown in Appendix A Table A1.

\section{Analysis}

The paper begins by examining how the associations between parental attributes and housing outcomes vary by gender and cohort. First, the odds of each outcome are calculated to assess trends in housing outcomes. Odds ratios are then used to evaluate how the relative chances of each housing outcome vary by family background. Odds ratios take into account changing structural conditions, allowing us to assess how inequalities in life chances have changed over time (Platt, 2005).

Multivariate models then assess how these associations are affected by life course trajectories and contextual conditions. Multinomial logistic regression is used as the dependent variable consists of four distinct unordered categories (Long \& Freese, 2006). Six separate models are estimated to allow the effects of each independent variable to vary by gender and cohort. ${ }^{9}$ Independent variables that did not contribute significantly to any model were not retained. Model estimates are reported as average marginal effects (AMEs). AMEs estimate the population average change in the probability of a specified outcome produced by changing a predictor while holding the rest of the variables at their observed values. 


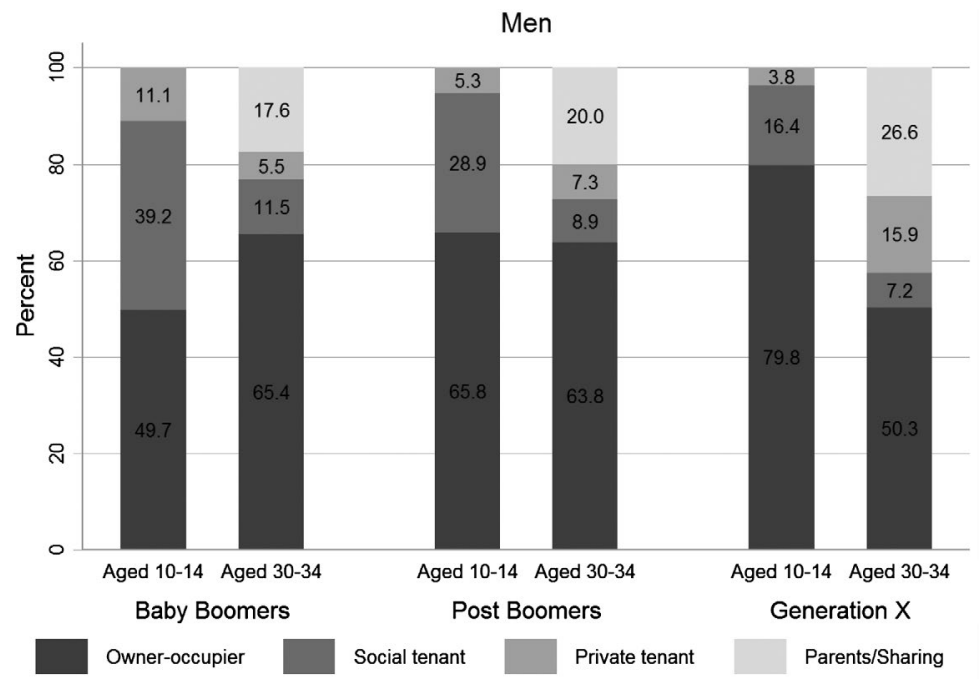

Figure 1a. Housing origins and outcomes by cohort: Men. Source: ONS Longitudinal Study (own analysis).

\section{Results}

\section{Descriptive analysis}

Figures $1 \mathrm{a}$ and $1 \mathrm{~b}$ show the percentage of men and women in each cohort who were in each housing state aged 10-14 and 30-34. In line with national trends the proportion of 10-14 year olds living in owner-occupation increased dramatically across the cohorts, while the proportion living in private and especially socially rented accommodation fell. Young adults' housing outcomes when aged 30-34 have also changed over time. Homeownership has become decreasingly common with the biggest drop occurring for Generation X (most notably amongst men). This is broadly consistent with Willetts' (2011) thesis that intergenerational wealth inequalities are deepening as the Baby Boomers enjoyed faster transitions into homeownership than more recent cohorts of young people. Although young women were consistently more likely than men to be social tenants, the total proportion of young adults living in social housing has declined over time as the sector contracted through Right to Buy sales and low levels of construction.

This decline has been counterbalanced by a renaissance of private renting amongst Generation X. This trend accounts for most of the decline in homeownership and social renting amongst women, for whom there was only a small increase in parental or shared living between the Post Boomer and Generation X cohorts. This increase may reflect greater participation in higher education and the postponement of partnership (Table A1, Appendix A). Rates of parental co-residence and sharing were consistently higher for young men who have also become increasingly likely to experience these outcomes over time. These gender patterns probably arise because women gain a 'head start' in their housing careers as they tend to form partnerships with older men. Rising lone motherhood during the 1980s and 1990s may also be relevant as the state supports lone parents to live independently through the benefit system and by providing priority access to the dwindling supply of social housing. As less support is provided to childless singles young men may have found it particularly difficult to maintain residential independence in the face of declining housing affordability 


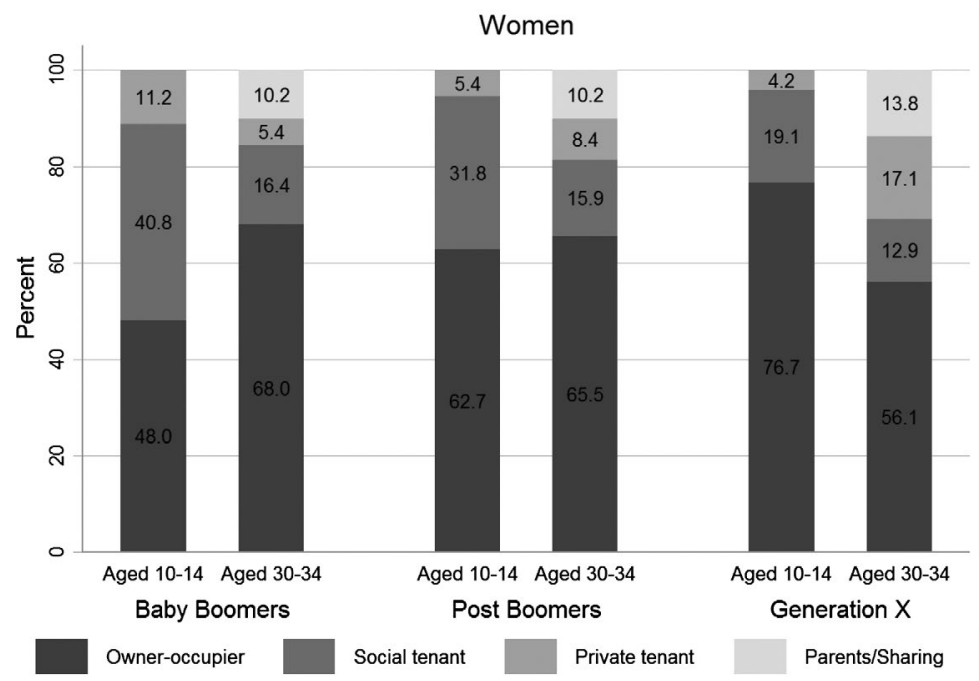

Figure 1b. Housing origins and outcomes by cohort: Women. Source: ONS Longitudinal Study (own analysis).

and a weakening youth labour market. This process is likely to have accelerated since 2011 with the curtailment of housing benefit support for single young people.

Tables $1 \mathrm{a}$ and $\mathrm{lb}$ show how the absolute and relative chances of each housing outcome vary by cohort and family background. Looking first at the absolute odds, the tables document a universal fall in owner-occupation across the cohorts. This is particularly pronounced for Generation X, who may have been constrained from entering homeownership by secular trends in affordability as well as the credit constraints and housing market stagnation induced by the Global Financial Crisis. Nevertheless, even in Generation X owner-occupation was the most likely housing outcome for most young people.

The odds of private renting and parental co-residence or sharing amongst men increased considerably in Generation X. By contrast, the odds of social renting fell across the cohorts, except for children whose parents were social tenants where the odds remained steady (for men) or increased (for women). In fact, Generation X women growing up in social housing are the only group for whom owner-occupation was not the most likely outcome. These women were most likely to be social tenants aged 30-34, while their male peers were almost as likely to be living with a parent or sharing as in owner-occupation. Over time, the children of social renters seem to have become particularly unlikely to enter owner-occupation as a greater proportion remain social tenants (women), become private renters (both genders) or live in the parental home or with other adults (men). This highlights the potency and persistence of long-term intergenerational continuities in housing disadvantage, although the contraction of the social rental sector and welfare reforms may in future make young people from less advantaged backgrounds more dependent on private rather than socially rented housing (Clapham et al., 2014).

Comparing the outcomes of children from different backgrounds using odds ratios (ORs) allows us to evaluate the changing openness of the housing system. ORs greater than one indicate that a group has higher odds of experiencing an outcome than the reference 


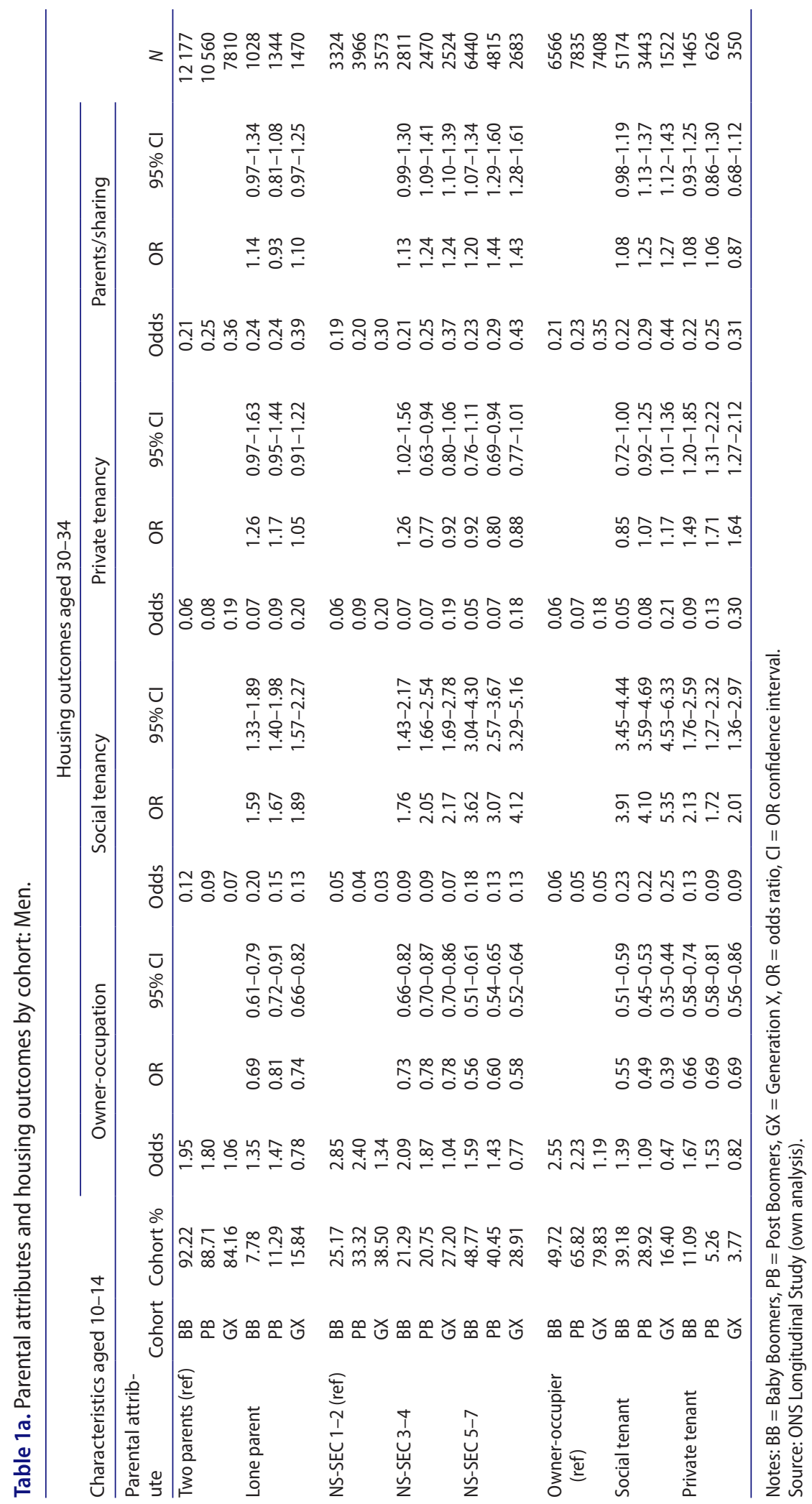




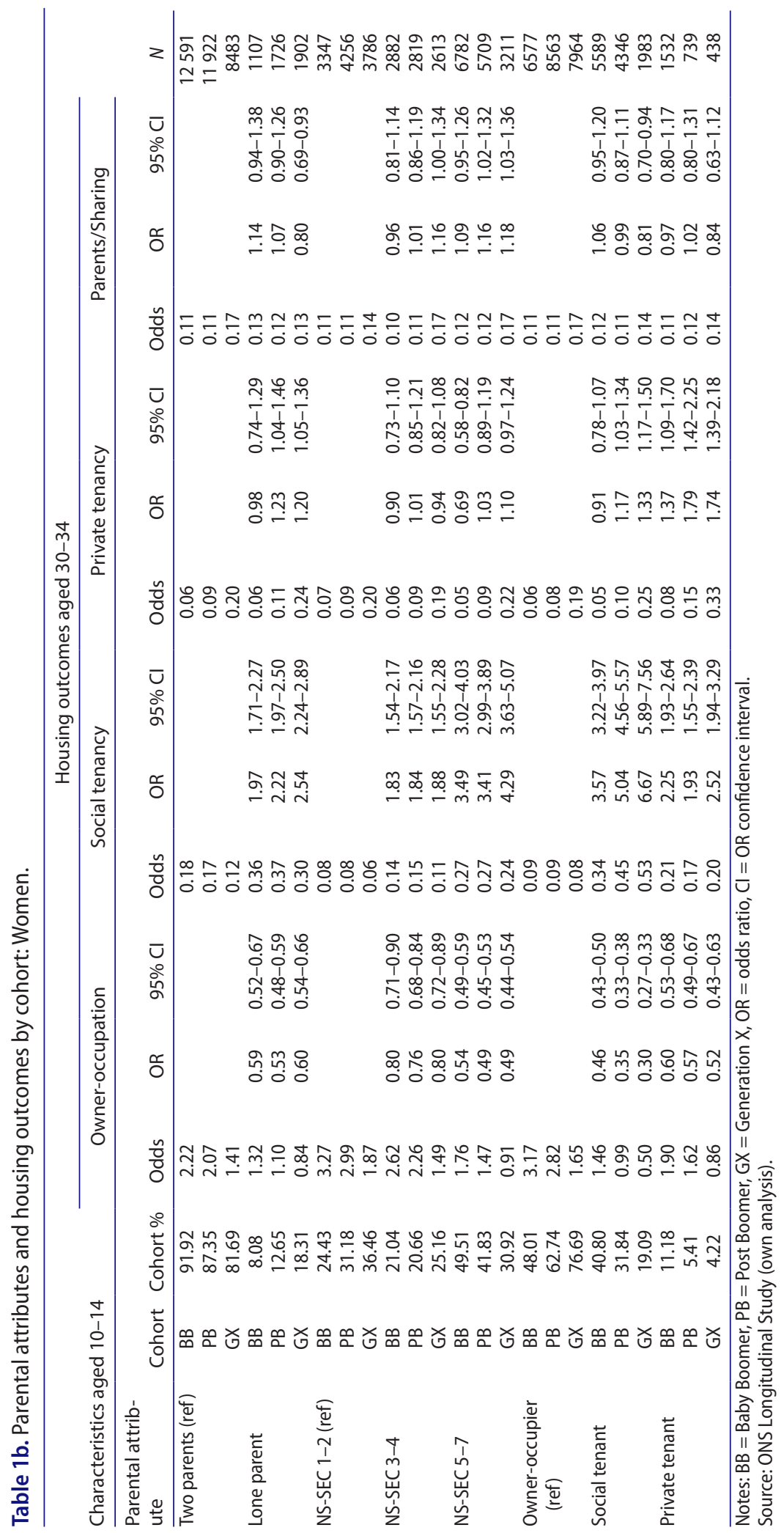


category, while ORs less than one indicate lower relative odds. ORs for each outcome are shown in Tables $1 \mathrm{a}$ and $1 \mathrm{~b}$ alongside their 95\% confidence intervals.

The odds of owner-occupation are consistently and significantly lower for the children of lone parents as compared with children from two parent families. By contrast, the ORs of social renting are significantly greater than one for the children of lone parents and this relationship has strengthened over time for women. For women, the relative odds of private renting are also significantly higher in more recent cohorts for the children of lone parents.

As the NS-SEC 3-4 category pools a varied group of occupations, focusing on the falling proportion of children with parents with routine occupational status (NS-SECs 5-7) provides the best way to assess the changing importance of class background. Across cohorts and genders roughly one child from a routine occupational background is an owner-occupier when 30-34 for every two with managerial or professional parents (NS-SECs 1-2). Social renting is much more likely for children with parents with a routine occupational background than for children with managerial and professional parents. Men and to a lesser extent women are also significantly more likely to be living with a parent or sharing if their parents had a routine occupational background. This indicates that children from working-class backgrounds are both less likely to own and live independently in early adulthood than their peers from more advantaged classes.

The ORs for parental tenure are particularly striking. For both genders the odds of owner-occupation are much lower for children whose parents were social tenants as compared with the children of owner-occupiers (the opposite is true for social tenancies). Furthermore, the ORs of owner-occupation for the children of social tenants have declined significantly across the cohorts while the ORs of social tenancy have significantly increased. This indicates strengthening intergenerational continuity in social tenancy and a decreasing relative propensity for the children of social tenants to become owner-occupiers. These patterns are gendered as Generation X men whose parents were social tenants are significantly more likely than men whose parents were owner-occupiers to subsequently live in privately rented accommodation or with their parents/other adults. By contrast, Generation X women whose parents were social tenants are less likely to be living with a parent or sharing than those whose parents were owner-occupiers. In all cohorts, the relative odds of owner-occupation are lower and the relative odds of becoming a tenant are greater for children growing up in privately rented accommodation. Overall, the results demonstrate that housing (dis) advantage is linked across generations in ways that have either remained consistent or strengthened slightly across time.

\section{Multinomial models}

Tables $2 \mathrm{a}$ and $2 \mathrm{~b}$ present AMEs from multinomial models examining whether contextual conditions or life course trajectories affect how family background is associated with housing outcomes. AMEs are reported for each category of the dependent variable. As AMEs estimate population average changes in probability the four AMEs for each variable sum to 0 . To facilitate discussion of the parental effects and prevent the over-interpretation of trends the estimated AMEs for the parental variables are displayed with their $95 \%$ confidence intervals in Appendix A Figures Ala and A1b. 


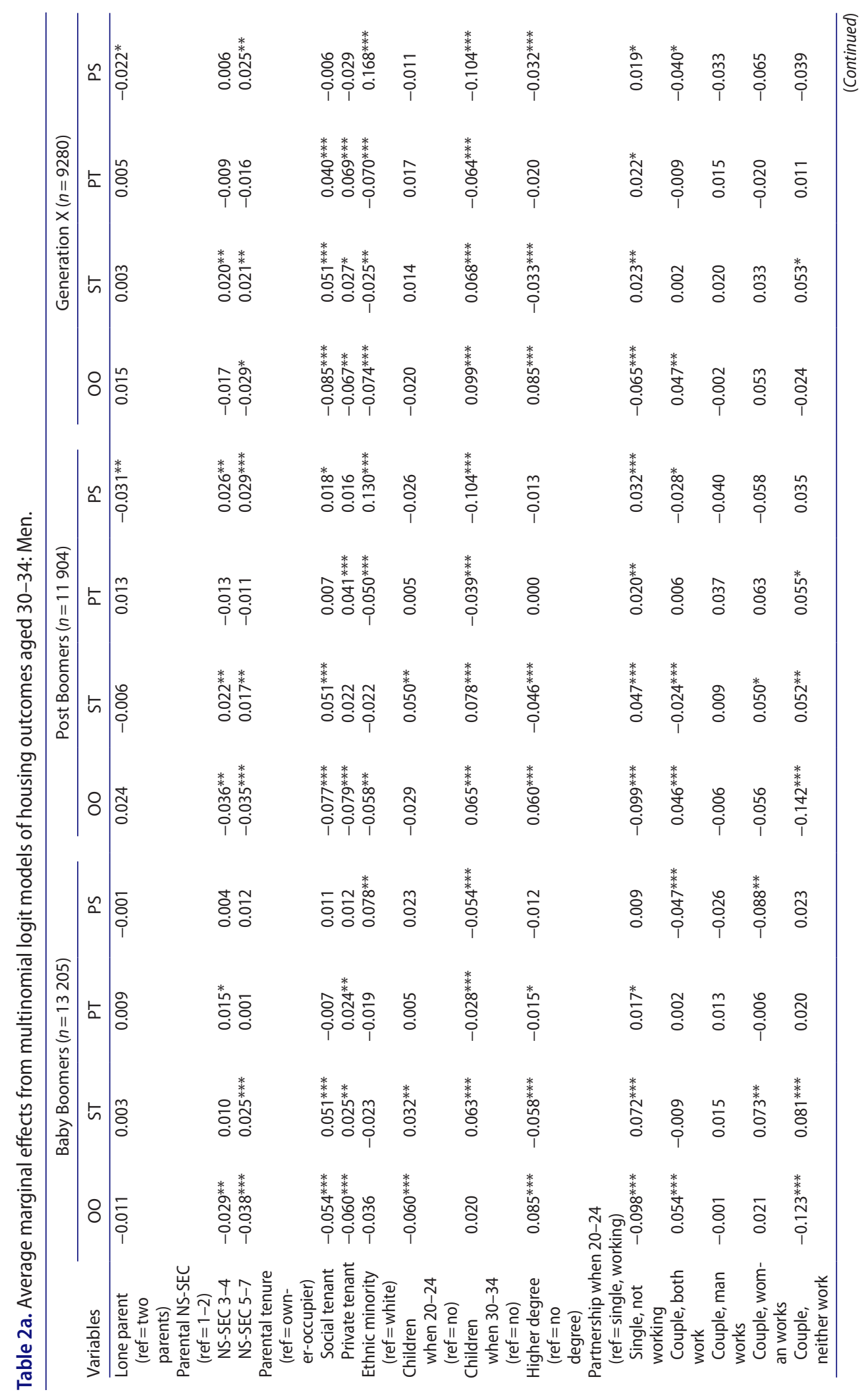




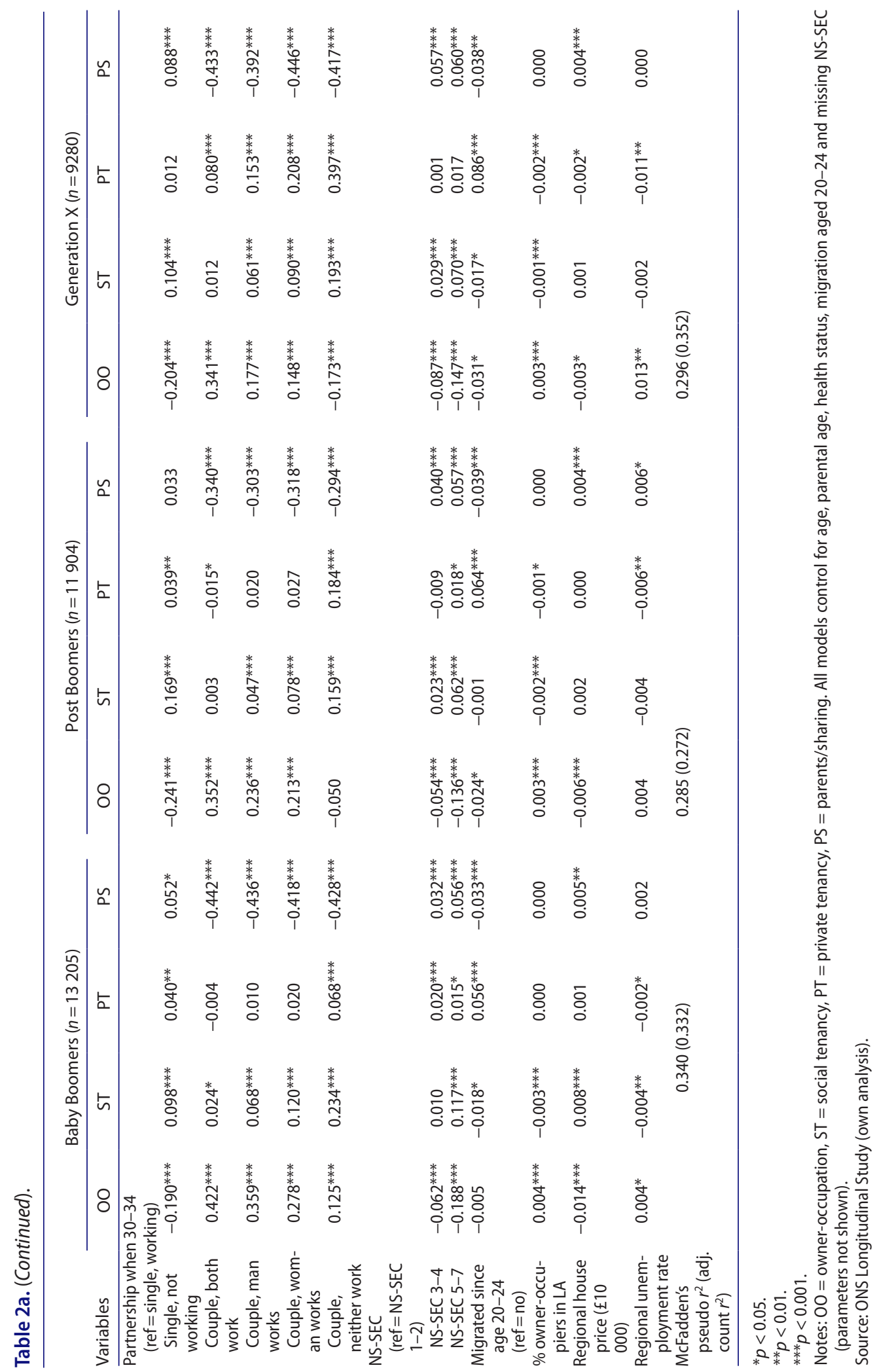




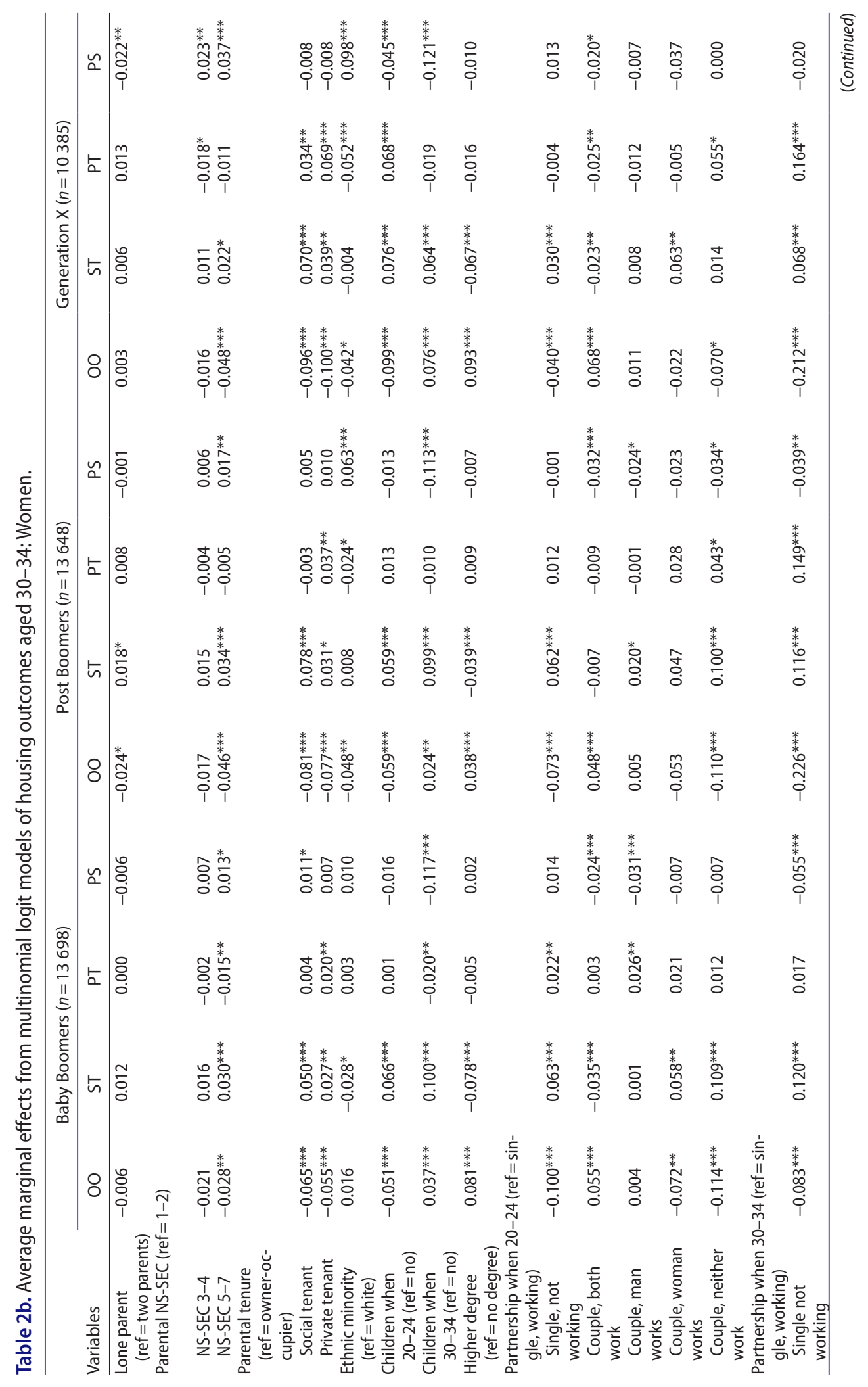




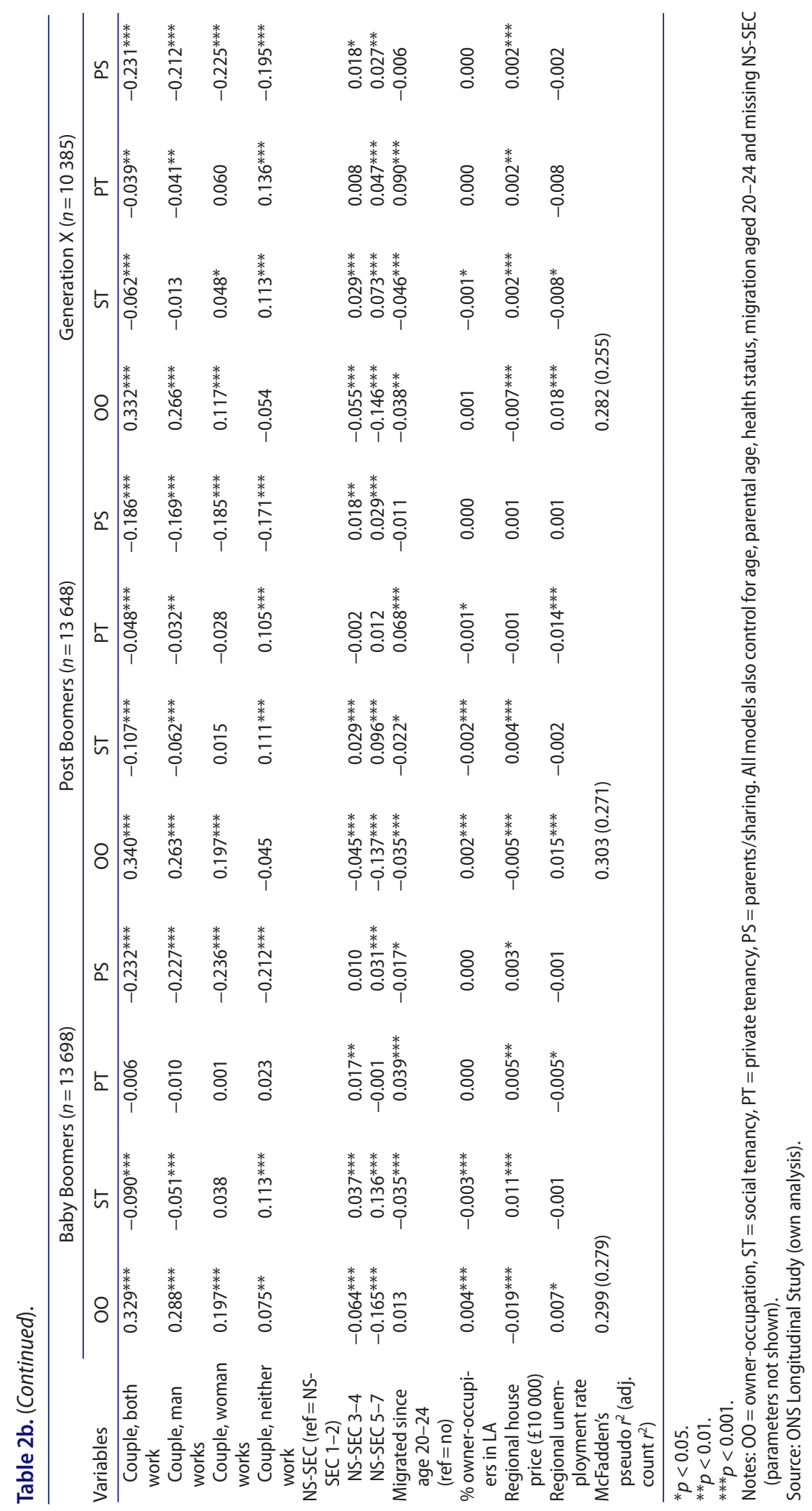


The models show that many parental attributes are independently associated with housing outcomes in early adulthood. In general, lone parenthood has fairly weak and insignificant effects. By contrast young adults in all cohorts are significantly less likely to become owner-occupiers and more likely to rent socially or live with parents/share (excepting male Baby Boomers) if their parents worked in routine occupations (NS-SEC 5-7) as compared with managerial and professional jobs (NS-SEC 1-2). Women from a routine occupational background have also become somewhat more likely to live in the parental home or share over time. Although this implies that working-class women may be finding it increasingly difficult to enter the housing system, overall the effects of parental occupational status seem to indicate more a persistence than deepening of class inequalities in housing outcomes.

The AMEs for parental tenure suggest that the late twentieth century expansion of owner-occupation was accompanied by the marginalisation of renting. The predicted probability of owner-occupation is significantly lower for the children of renters as compared with homeowners and this relative gap seems to have widened slightly across the cohorts. ${ }^{10}$ This provides some support for concerns that homeownership is increasingly unattainable to children whose parents rent, although the secular decline in homeownership amongst young adults is a much more pronounced trend.

There is a strong intergenerational association of social tenancy in all cohorts, as well a strengthening link between parental tenancy and the probability of subsequent private renting. This finding is important as debates about the tribulations of Generation Rent often overlook that it is children from less privileged backgrounds who are becoming disproportionately reliant on the private rental sector. One explanation for these trends is that renting (especially social renting) became 'residualised' during the late twentieth century as those who could afford it increasingly moved into owner-occupation. While we cannot rule out the possibility that selection explains the parental tenure effects (Aratani, 2011), the fact that these are net of life course characteristics as well as parental class and family structure hints that any selection effects are probably quite minor.

Many life course variables have close links to housing outcomes. Ethnic minorities in recent cohorts have a significantly lower probability of owning and a higher probability of parental co-residence or sharing than whites. The latter effect is particularly pronounced amongst more recent cohorts of men. Women have a significantly lower probability of owner-occupation and a greater probability of renting socially (and privately for Generation X) if they had children when 20-24. This might reflect the allocation of scarce social housing to young lone parents. Living with children when $30-34$ is associated with a higher probability of owner-occupation or social renting as well as a lower probability of parental co-residence/ sharing or renting privately (for men). In all cohorts having a degree increases the probability of owner-occupation while reducing the probability of social tenancy.

Being single and not working aged 20-24 and especially when 30-34 reduces the probability of owner-occupation and increases the probability of renting socially relative to working singles. Living as a couple when 30-34 greatly reduces the probability of living with a parent or sharing, even if neither partner is in work. By contrast, the relative probability of owner-occupation is higher if living in a dual- or to a lesser extent single-earner partnership when 30-34. The particularly strong effects for dual-earner couples may reflect the need for two incomes to sustain homeownership. The relative probability of renting socially is greater if living as a workless couple, although the relative chance that workless couples rent privately has risen across time. 
Unsurprisingly, the predicted probability of owner-occupation is lower if individuals have a routine as compared with a managerial or professional class position. Men and women with a routine occupational class are also relatively more likely to rent socially (particularly women) or live with a parent or other adults (especially men). Recent migration is associated with a significantly higher probability of renting privately.

Adding contextual variables significantly improved the fit of all models. As expected, a greater proportion of owners in the LA raises the probability of owning and lowers the probability of renting. In all cohorts higher regional house prices dampen the probability of owner-occupancy, although these effects appear to have weakened over time. Gender seems to mediate how young people adapt to housing costs as high house prices more strongly increase the probability that men live with parents or share their dwelling as compared with women. By contrast, the probability that Baby Boomer and Generation X women (but not men) rent privately is higher in more expensive regions. Higher regional unemployment is linked to a greater probability of owner-occupancy. This is in line with evidence that rates of homeownership and unemployment are correlated (De Graaff and van Leuvensteijn, 2013).

\section{Conclusions}

There is growing concern that young adults' increasingly constrained housing options are deepening the intergenerational inequalities of wealth and security that are emerging with population ageing, globalisation and the retreat of welfare states. Difficulties entering the housing system and especially homeownership are also thought to be making young adults' housing position more dependent on family support (McKee, 2012). As housing is a major component of household outgoings and assets, deepening reliance on family support could hinder social mobility and exacerbate inequality as young people from more advantaged backgrounds are insulated from the growing housing risks and constraints faced by their less advantaged peers. In consequence, this paper has examined how the housing outcomes of three cohorts of young adults are linked to the attributes of their parents in a liberal context where social mobility is an explicit aim of government policy.

The results show that young adults' housing careers have changed over time in ways that could exacerbate inequalities of wealth and housing security between cohorts. The likelihood that young people from all backgrounds are homeowners has dropped over time while private renting and parental living or sharing have become much more common. This fits with a broader shift towards more fluid and precarious transitions to adulthood. Overall, the magnitude of these cohort patterns seems to dwarf the much more modest temporal trends we observe in the relationships between family background and young adults' housing outcomes.

In general, parental socio-economic (dis)advantage has been persistently associated with the stratification of young adults' housing outcomes in recent decades. Ceteris paribus owner-occupation is less likely and social tenancies or parental co-residence/sharing are more likely for young people whose parents worked in routine or manual jobs. Although the proportion of young people with managerial and professional parents has increased over time, this has not been accompanied simply by class polarisation of housing outcomes. For men the relative probabilities of owner-occupation by class have changed little over time. By contrast, the relative probability of owner-occupation appears to have declined slightly over time, while the relative probability of parental living or sharing has increased for women 
with parents from a routine occupational background. This suggests that working-class women are finding it increasingly difficult to enter the housing system, perhaps due to the contraction of the social rental sector. However, in general the effects of parental class seem relatively stable across cohorts.

Two factors complicate this picture. As the proportion of children with managerial and professional parents increased over time, it is likely that this group became more diverse and relatively less advantaged in ways that are hard to measure. Furthermore, the modelled parental NS-SEC effects probably underestimate the cumulative importance of parental class. Intergenerational continuities in educational attainment, labour force attachment and occupation mean that much of the impact of parental class may be indirectly transmitted through young adults' life course development (Ermisch \& Halpin, 2004).

The strong links between parental tenure and child housing outcomes also indicate persistent intergenerational continuities in housing (dis)advantage. Even after controlling for life course factors, the children of tenants are significantly less likely to be homeowners and often significantly more likely to be renting aged 30-34 than the children of homeowners. As this finding persists across cohorts and has been documented in other Western countries, it is clear that homeownership is transmitted between generations under a wide range of contextual conditions. Although the model estimates are subject to some uncertainty, in general young people's housing outcomes also appear to be polarising slightly by parental tenure. The children of renters have become increasingly likely to become private renters over time both in absolute terms and relative to the children of owner-occupiers. Although Generation X has been dubbed 'Generation Rent', the odds of owner-occupation seem to have declined most strongly over time for the children of renters (particularly social tenants). This suggests that renters became a marginalised minority in the latter part of the twentieth century and that this may have constrained their children's housing options and social mobility prospects. Further work should examine whether this pattern holds in other Western societies where the rental system is less starkly divided into a private market and a residualised social sector.

Several aspects of the results require further analysis. First, debates about the impacts of postponed homeownership on fertility and young families highlight how it may be the timing rather than the occurrence of housing transitions that varies by cohort and/or parental background. For example, the children of renters may take longer to enter owner-occupation than children with homeowner parents. The impact of parental tenure may thus change as children age, although any duration effects will still have financial and policy implications. Moreover, parental tenure is not necessarily constant over time and it is not clear when it is most relevant to young people. Examining these issues and disentangling them from the period effects of the Global Financial Crisis will require very long periods of longitudinal data gathered retrospectively or at frequent intervals from both parents and children.

Care is also required when interpreting the parental tenure effects given the changing composition and social meaning of tenure categories over time. Long-term intergenerational associations richly describe social fluidity but they cannot reveal the mechanisms by which parental tenure shapes children's housing outcomes. Given the strong British ideology of homeownership, it seems probable that differential access to resources rather than socialisation is the key mechanism. Owners and renters may also differ in unobserved ways which could have changed over time, for instance if renting has become an increasingly strong proxy for unmeasured disadvantage. However, even if this were the case the 
results demonstrate that this disadvantage could be compounded by inequalities in young adults' subsequent housing trajectories. Finally, parental tenure may have different effects for different groups and further research into interaction effects remains necessary.

Finally, the results emphasise that gaining a richer understanding of current and future housing inequalities requires looking beyond intergenerational transmission. Demography plays a central role in the stratification of young adults' housing trajectories with divergence by factors such as gender, ethnicity and partnership status. Housing outcomes are also configured by house prices and tenure mix, implying that the geography of housing markets strongly affects young adults' housing outcomes and the money they spend, gain and lose in the housing system. Evaluating the open- and fairness of housing systems requires considering how inequalities are generated within cohorts as well as how they are transmitted across generations.

\section{Notes}

1. The British rental system consists of a private market and a largely separate social rental sector where housing is bureaucratically allocated at below market rents. More vulnerable groups generally receive priority access to social housing.

2. Children could leave compulsory education at 15 until 1972.

3. This could partly reflect gendered migration patterns.

4. Further analysis suggested that roughly two-thirds of the group lived with a parent. This proportion changed little over time and men were consistently more likely to live with a parent than women.

5. Values are derived from the person's current job or their most recent occupation if not in work.

6. The census does not record incomes.

7. Information on qualifications obtained before age 18 was not consistently collected by the census until 2001.

8. The average price paid by first-time buyers should capture the cost of the types of dwelling accessible to young adults better than the average overall house price.

9. This also allows the 'meaning' of variables to change over time. For example, higher degrees may have become a weaker indicator of socio-economic advantage over time as the proportion of adults attending university has risen.

10. Without data spanning a longer period it is impossible to tell whether this is because the children of renters are taking comparatively longer to attain homeownership, or because they are becoming relatively less likely ever to own.

\section{Acknowledgements}

The permission of the Office for National Statistics (ONS) to use the Longitudinal Study is gratefully acknowledged, as is the invaluable help provided by staff of the Centre for Longitudinal Study Information \& User Support (CeLSIUS). CeLSIUS is supported by the ESRC Census of Population Programme [ES/K000365/1]. I bear sole responsibility for all analyses and interpretations of the data. This work contains statistical data from ONS which is Crown Copyright. The use of ONS statistical data in this work does not imply endorsement of the ONS in relation to the interpretation or analysis of the statistical data. This work uses research datasets which may not exactly reproduce National Statistics aggregates.

The derivation of NS-SEC classes is provided in Bukodi and Neuburger (2009) 'Data Note. Job and occupational histories for the NSHD 1946 Birth Cohort' as part of the ESRC Gender Network Grant, Project 1 'Changing occupational careers of men and women' (RES-225-25-2001). The code was kindly provided by Erzsebet Bukodi and adapted for use in the LS by Franz Buscha and Patrick 
Sturgis as part of the ESRC grant 'Inter-cohort Trends in Intergenerational Mobility in England and Wales: Income, status, and class (InTIME)' [ES/K003259/1].

I would like to thank Bill Clark, John Flint, Clara Mulder, Michael Oxley, Jacqueline Scott and the three anonymous reviewers for their critical comments and suggestions. Discussions at the ESRC Centre for Population Change, TU Delft and the 2015 Housing Studies Association conference also enhanced this paper.

\section{Disclosure statement}

No potential conflict of interest was reported by the author.

\section{Funding}

This work was supported by an Economic and Social Research Council (ESRC) Future Research Leaders award [grant number ES/L009498/1]. Additional financial support was provided by the Isaac Newton Trust.

\section{ORCID}

Rory Coulter (D) http://orcid.org/0000-0002-0773-8919

\section{References}

Andrew, M. (2012) The changing route to owner-occupation: The impact of borrowing constraints on young adult homeownership transitions in Britain in the 1990s, Urban Studies, 49(8), pp. 1659-1678.

Appleyard, L. \& Rowlingson, K. (2010) Home Ownership and the Distribution of Personal Wealth: A Review of the Evidence (York: Joseph Rowntree Foundation).

Aratani, Y. (2011) Socio-demographic variations of homeowners and differential effects of parental homeownership on offspring's housing tenure, Housing Studies, 26(5), pp. 723-746.

Blaauboer, M. (2010) Family background, individual resources and the homeownership of couples and singles, Housing Studies, 25(4), pp. 441-461.

Buxton, J., Clarke, L., Grundy, E. \& Marshall, C. E. (2005) The long shadow of childhood: Associations between parental social class and own social class, educational attainment and timing of first birth; results from the ONS Longitudinal Study, Population Trends, 121(Autumn), pp. 17-26.

Clapham, D., Mackie, P., Orford, S., Thomas, I. \& Buckley, K. (2014) The housing pathways of young people in the UK, Environment and Planning A, 46(8), pp. 2016-2031.

Clark, W. A. V. \& Mulder, C. H. (2000) Leaving home and entering the housing market, Environment and Planning A, 32(9), pp. 1657-1671.

De Graaff, T. \& Van Leuvensteijn, M. (2013) A European cross-country comparison of the impact of homeownership and transaction costs on job tenure, Regional Studies, 47, pp. 1443-1461.

Di Salvo, P. \& Ermisch, J. (1997) Analysis of the dynamics of housing tenure choice in Britain, Journal of Urban Economics, 42, pp. 1-17.

Ermisch, J. (1999) Prices, parents, and young people's household formation, Journal of Urban Economics, 45(1), pp. 47-71.

Ermisch, J. \& Halpin, B. (2004) Home ownership and social inequality in Britain, in: K. Kurz \& H.-P. Blossfeld (Eds) Home Ownership and Social Inequality in Comparative Perspective, pp. 255-280 (Stanford: Stanford University Press).

Forrest, R. \& Murie, A. (1995) Accumulating evidence: Housing and family wealth in Britain, in: R. Forrest \& A. Murie (Eds) Housing and Family Wealth: Comparative International Perspectives, pp. 58-85 (London: Routledge). 
Gardiner, L. \& Alakeson, V. (2014) The Home Stretch: Coping with High Housing Costs (London: Resolution Foundation).

Hamnett, C. (1999) Winners and Losers: Home Ownership in Modern Britain (London: UCL Press). Heath, S. \& Calvert, E. (2013) Gifts, loans and intergenerational support for young adults, Sociology, 47(6), pp. 1120-1135.

Helderman, A. \& Mulder, C. H. (2007) Intergenerational transmission of homeownership: The roles of gifts and continuities in housing market characteristics, Urban Studies, 44(2), pp. 231-247.

Henretta, J. C. (1984) Parental status and child's home ownership, American Sociological Review, 49(1), pp. 131-140.

Jenkins, S. P. \& Maynard, A. K. (1983) Intergenerational continuities in housing, Urban Studies, 20(4), pp. 431-438.

Kennett, P., Forrest, R. \& Marsh, A. (2013) The global economic crisis and the reshaping of housing opportunities, Housing, Theory and Society, 30(1), pp. 10-28.

Kurz, K. \& Blossfeld, H-P. (2004) Introduction: Social stratification, welfare regimes, and access to homeownership, in: K. Kurz \& H.-P. Blossfeld (Eds) Home Ownership and Social Inequality in Comparative Perspective, pp. 1-20 (Stanford: Stanford University Press).

Lennartz, C., Arundel, R. \& Ronald, R. (2015) Younger adults and homeownership in Europe through the Global Financial Crisis, Population, Space and Place. doi:http://dx.doi.org/10.1002/psp.1961.

Lersch, P. M. \& Luijkx, R. (2015) Intergenerational transmission of homeownership in Europe: Revisiting the socialisation hypothesis, Social Science Research, 49, pp. 327-342.

Long, J. S. \& Freese, J. (2006) Regression Models for Categorical Dependent Variables Using Stata, 2nd ed. (College Station, TX: Stata Press).

McKee, K. (2012) Young people, homeownership and future welfare, Housing Studies, 27(6), pp. $853-862$.

Mulder, C. H. \& Smits, J. (1999) First-time home-ownership of couples: The effect of inter-generational transmission, European Sociological Review, 15(3), pp. 323-337.

Mulder, C. H. \& Smits, A. (2013) Inter-generational ties, financial transfers and home-ownership support, Journal of Housing and the Built Environment, 28(1), pp. 95-112.

Murphy, M. J. (1984) The influence of fertility, early housing-career, and socioeconomic factors on tenure determination in contemporary Britain, Environment and Planning A, 16(10), pp. 13031318.

National Housing Federation (2014) Home Truths 2014/15: Broken Market, Broken Dreams (London: NHF).

Öst, C. E. (2012) Parental wealth and first-time homeownership: A cohort study of family background and young adults' housing situation in Sweden, Urban Studies, 49(10), pp. 2137-2152.

Payne, J. \& Payne, G. (1977) Housing pathways and stratification: A study of life chances in the housing market, Journal of Social Policy, 6(2), pp. 129-156.

Platt, L. (2005) The intergenerational social mobility of minority ethnic groups, Sociology, 39(3), pp. $445-461$.

Saunders, P. (1990) A Nation of Homeowners (London: Unwin Hyman).

Shelter (2014) The Clipped Wing Generation: Analysis of Adults Living at Home with their Parents (London: Shelter).

Smits, A. \& Mulder, C. H. (2008) Family dynamics and first-time homeownership, Housing Studies, 23(6), pp. 917-933.

Spilerman, S. \& Wolff, F. C. (2012) Parental wealth and resource transfers: How they matter in France for home ownership and living standards, Social Science Research, 41(2), pp. 207-223.

Stone, J., Berrington, A. \& Falkingham, J. (2011) The changing determinants of UK young adults' living arrangements, Demographic Research, 25, pp. 629-666.

Stone, J., Berrington, A. \& Falkingham, J. (2014) Gender, turning points, and boomerangs: Returning home in young adulthood in Great Britain, Demography, 51(1), pp. 257-276.

Tatch, J. (2007) Affordability-Are parents helping? Housing Finance, 3, pp. 1-11.

Watt, P. (1996) Social stratification and housing mobility, Sociology, 30(3), pp. 533-550.

Willetts, D. (2011) The Pinch: How the Baby Boomers Took Their Children's Future - And Why They Should Give It Back (London: Atlantic Books). 


\section{Appendix A}

Figure A1a. AMEs and 95\% confidence intervals for parental attributes: Men. Source: ONS Longitudinal Study (own analysis).
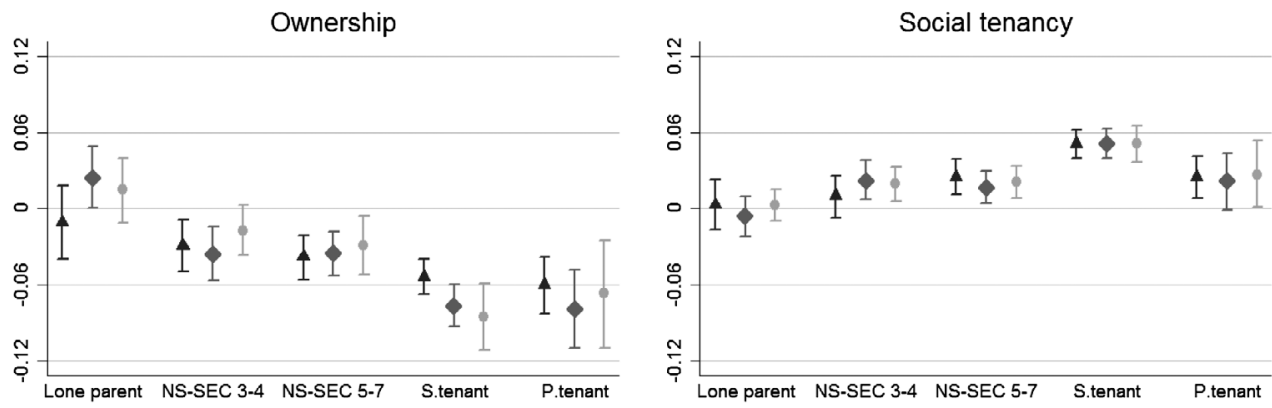

Private tenancy
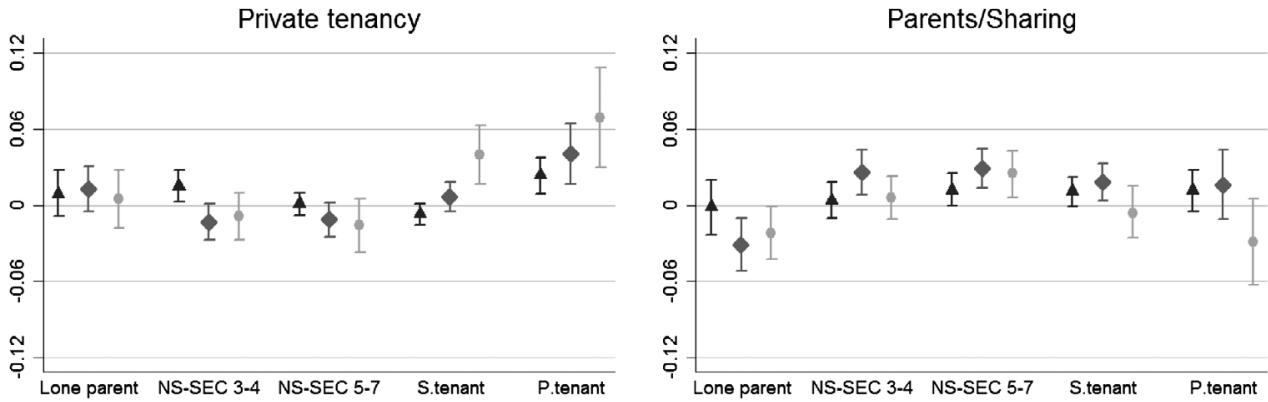

$\Delta$ Baby Boomer

Post Boomer

- Generation X

Figure A1b. AMEs and 95\% confidence intervals for parental attributes: Women. Source: ONS Longitudinal Study (own analysis).
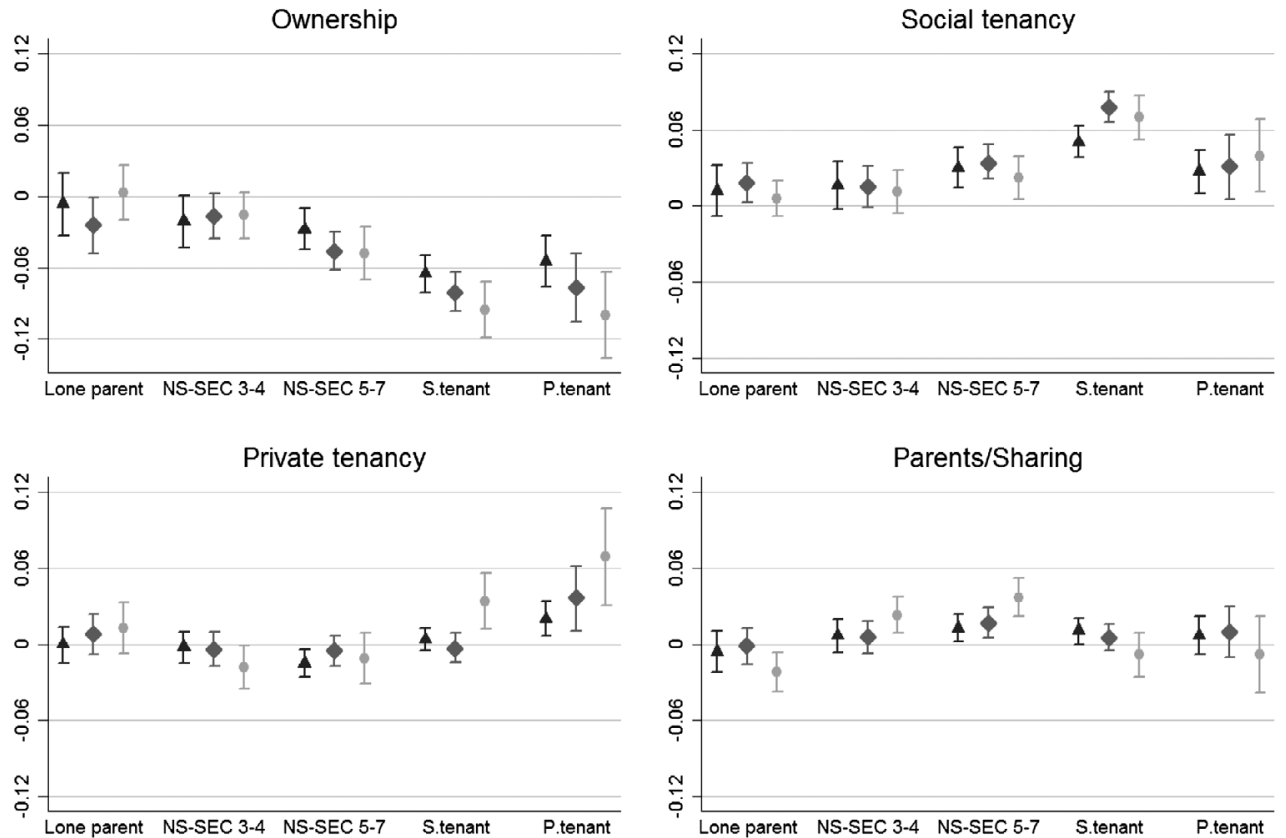
Table A1. Descriptive statistics.

\begin{tabular}{|c|c|c|c|c|c|c|}
\hline \multirow[b]{2}{*}{ Categorical variables (\%) } & \multicolumn{2}{|c|}{ Baby Boomers } & \multicolumn{2}{|c|}{ Post Boomers } & \multicolumn{2}{|c|}{ Generation X } \\
\hline & Men & Women & Men & Women & Men & Women \\
\hline \multicolumn{7}{|l|}{ Parental family type (ref = two parents) } \\
\hline Lone parent & 7.8 & 8.1 & 11.3 & 12.6 & 15.8 & 18.3 \\
\hline \multicolumn{7}{|c|}{ Parental NS-SEC (ref $=1-2$, managerial/professional) } \\
\hline 3-4 (intermediate) & 21.3 & 21.0 & 20.7 & 20.7 & 27.2 & 25.2 \\
\hline 5-7 (routine and manual) & 48.8 & 49.5 & 40.4 & 41.8 & 28.9 & 30.9 \\
\hline Undefined/missing & 4.8 & 5.0 & 5.5 & 6.3 & 5.4 & 7.5 \\
\hline \multicolumn{7}{|l|}{ Parental tenure (ref = owner-occupation) } \\
\hline Social tenant & 39.2 & 40.8 & 28.9 & 31.8 & 16.4 & 19.1 \\
\hline Private tenant & 11.1 & 11.2 & 5.3 & 5.4 & 3.8 & 4.2 \\
\hline \multicolumn{7}{|l|}{ Ethnicity (ref = white) } \\
\hline Ethnic minority & 2.4 & 2.4 & 3.7 & 4.3 & 8.0 & 7.7 \\
\hline \multicolumn{7}{|l|}{ Health status (ref $=$ no LLTI) } \\
\hline LLTI & 4.8 & 4.4 & 8.1 & 7.8 & 7.0 & 7.5 \\
\hline \multicolumn{7}{|l|}{ Children when 20-24 (ref = no children) } \\
\hline Children & 11.9 & 27.1 & 8.0 & 24.1 & 4.6 & 19.9 \\
\hline \multicolumn{7}{|l|}{ Children when 30-34 (ref = no children) } \\
\hline Children & 55.7 & 74.3 & 45.2 & 67.0 & 38.1 & 60.2 \\
\hline \multicolumn{7}{|l|}{ Higher degree (ref = no degree) } \\
\hline Higher degree & 11.8 & 7.9 & 20.1 & 18.0 & 39.2 & 43.1 \\
\hline \multicolumn{7}{|l|}{ Partnership when 20-24 (ref = single, working) } \\
\hline Single, not working & 15.4 & 12.1 & 16.9 & 17.2 & 26.6 & 28.9 \\
\hline Couple, both work & 14.7 & 24.0 & 15.7 & 25.8 & 10.3 & 20.5 \\
\hline Couple, man works & 9.9 & 19.3 & 4.8 & 9.6 & 3.2 & 6.0 \\
\hline Couple, woman works & 1.2 & 2.0 & 0.9 & 1.5 & 0.7 & 1.3 \\
\hline Couple, neither work & 2.9 & 4.7 & 2.0 & 3.4 & 1.5 & 2.6 \\
\hline \multicolumn{7}{|l|}{ Partnership when 30-34 (ref = single, working) } \\
\hline Single, not working & 5.3 & 8.4 & 6.1 & 10.2 & 7.0 & 9.0 \\
\hline Couple, both work & 43.4 & 45.7 & 48.5 & 49.4 & 49.3 & 51.5 \\
\hline Couple, man works & 24.1 & 24.3 & 15.3 & 15.6 & 9.9 & 10.6 \\
\hline Couple, woman works & 2.1 & 2.5 & 1.8 & 2.1 & 1.9 & 2.2 \\
\hline Couple, neither work & 4.5 & 4.6 & 2.4 & 3.1 & 1.9 & 2.8 \\
\hline \multicolumn{7}{|l|}{ NS-SEC (ref $=1-2$, managerial/professional) } \\
\hline 3-4 (intermediate) & 28.2 & 29.2 & 20.0 & 21.4 & 20.3 & 22.1 \\
\hline 5-7 (routine and manual) & 31.8 & 28.5 & 28.4 & 27.3 & 21.7 & 19.5 \\
\hline Undefined/missing & 1.0 & 3.9 & 1.1 & 1.7 & 1.5 & 1.9 \\
\hline \multicolumn{7}{|l|}{ Migration since age 10-14 (ref = no migration) } \\
\hline Migrated & 11.6 & 13.4 & 12.0 & 13.8 & 17.7 & 19.1 \\
\hline \multicolumn{7}{|l|}{ Migration since age $20-24$ (ref = no migration) } \\
\hline Migrated & 17.0 & 15.7 & 15.8 & 15.4 & 20.2 & 21.1 \\
\hline \multicolumn{7}{|l|}{ Continuous variables (mean) } \\
\hline Age of parent at LSM's birth & 27.9 & 27.9 & 26.7 & 26.6 & 27.0 & 26.7 \\
\hline Age of LSM & 32.0 & 32.0 & 32.1 & 32.1 & 31.9 & 31.9 \\
\hline$\%$ owner-occupiers in LA district & 68.3 & 68.4 & 70.1 & 70.0 & 65.0 & 65.3 \\
\hline Mean regional house price ( $£ 2011 / 10000)$ & 7.5 & 7.5 & 10.8 & 10.8 & 17.0 & 16.7 \\
\hline Regional unemployment rate & 10.0 & 6.0 & 5.4 & 4.4 & 6.6 & 5.9 \\
\hline$N$ cases & 13205 & 13698 & 11904 & 13648 & 9280 & 10385 \\
\hline
\end{tabular}

Notes: LLTI = long-term limiting illness or disability. Non-parental variables measured when aged 30-34 unless otherwise stated.

Source: ONS Longitudinal Study (own analysis). 